Article title: The Application of Theoretical and Conceptual Frameworks in Open and Distance Learning Research Authors: Scholastica Chizoma Ukwoma[1], Patrick Ngulube[2]

Affiliations: School of Interdisciplinary Research and Graduate Studies, University of South Africa[1]

Orcid ids: 0000-0001-7164-8371[1], 0000-0002-7676-3931[2]

Contact e-mail: scholar.ukwoma@unn.edu.ng

License information: This work has been published open access under Creative Commons Attribution License $\mathrm{http}: / / c r e a t i v e c o m m o n s . o r g / l i c e n s e s / b y / 4.0 /$, which permits unrestricted use, distribution, and reproduction in any medium, provided the original work is properly cited. Conditions, terms of use and publishing policy can be found at https://www.scienceopen.com/.

Preprint statement: This article is a preprint and has not been peer-reviewed, under consideration and submitted to UnisaRxiv for open peer review.

DOI: 10.25159/UnisaRxiv/000023.v1

Preprint first posted online: 09 June 2021

Keywords: conceptual framework, theoretical framework, open and distance learning, theory use 


\section{The Application of Theoretical and Conceptual Frameworks in Open and Distance Learning Research}

\author{
Scholastica Chizoma Ukwoma \\ https://orcid.org/0000-0001-7164-8371 \\ School of Interdisciplinary Research \\ and Graduate Studies, University of \\ South Africa \\ University of Nigeria \\ scholar.ukwoma@unn.edu.ng
}

\author{
Patrick Ngulube \\ https://orcid.org/0000-0002-7676-3931 \\ School of Interdisciplinary Research \\ and Graduate Studies, University of \\ South Africa \\ ngulup@unisa.ac.za
}

\section{Abstract}

Conceptual and theoretical frameworks are the major ingredients of social research. Conceptual or theoretical frameworks assist researchers in framing their studies and explaining social phenomenon. Many researchers have difficulties in applying and understanding the utility of conceptual or theoretical frameworks when conducting research. The purpose of this study was to investigate the application and understanding of conceptual and theoretical frameworks in open and distance education. Using content analysis, the researchers studied a total of 336 open and distance learning research articles from five core open and distance education journals. It was discovered that the use of one theory in a study is more prevalent. In most cases where more than one theory was used, the researchers referred to it as a theoretical framework. In some studies, they confused theoretical with conceptual frameworks. Some researchers regarded research frameworks, such as paradigms, as theoretical frameworks. Many studies did not explain the way in which conceptual and theoretical frameworks helped them to design their research. Furthermore, researchers did not demonstrate how and why a theory was more applicable to their studies than an alternative one. The study identified that there is a need for more clarification of these concepts when they are used by researchers.

Keywords: conceptual framework, theoretical framework, open and distance learning, theory use

\section{Introduction}

Theory is important in research; it is one of the major pillars of research (Ngulube 2020). The use of theory not only helps in explaining the research variables, but it also contributes to the production of transformative knowledge (Ngulube 2020). This partly explains why many disciplines use theory in their research to explain the research variables and their realities. Kitchel and Ball (2014) defined theory and theoretical framework as a statement or complex argument explaining and/or predicting 
phenomena. On the other hand, a conceptual framework is the logical conceptualisation of your entire research project (Kivunja 2018). Kitchel and Ball (2014) highlight that a conceptual framework indicates that a relationship exists, but lacks the rationale behind the relationship. "The theoretical framework for your research proposal or thesis is not a summary of your own thoughts about your research. Rather, it is a synthesis of the thoughts of giants in your field of research, as they relate to your proposed research or thesis" (Kivunja 2018, 46). The major similarity between a theoretical framework and a conceptual framework is that they are both conceptual tools that are fundamental to empirical research (Ngulube 2018). Theoretical and conceptual frameworks guide the researcher when choosing what variable to include and measure in a study.

It has been observed that researchers have a misconception of the use of theories and conceptual frameworks. Adom, Hussein and Agyem (2018) stated that many researchers apply the two concepts incorrectly in their research work. As a result, their research findings become weak because of the inappropriate application of a theoretical framework and/or conceptual framework. Some even use concepts from theories and regard the framework as theoretical rather than as conceptual. Some fall into the trap of theory dropping and theory diversification. This situation also affects researchers from disciplines such as open and distance learning (ODL). This study was conducted to ascertain the extent to which ODL researchers use theoretical and conceptual frameworks in their research.

The research questions that guided the study were as follows:

- To what extent do researchers in ODL use theory?

- To what extent do ODL researchers use more than one theory in one study?

- How many ODL researchers use aspects of the theory and still call it a theoretical framework?

- How many ODL researchers use many theories and still call them a theoretical framework, without a focus on theory triangulation?

- To what extent do ODL researchers mention theories and never show the utility of the theory to the study?

- To what extent do ODL researchers borrow theories from other disciplines?

\section{Classification of the Indicators}

Theoretical and conceptual frameworks are two important aspects of the research process. Although the terms seem similar, they are different in terms of concepts and roles in research inquiry (Adom, Hussein, and Agyem 2018). Crawford (2020) likened the theoretical framework to a foundation for a house, providing essential support for the study component and clarifying the context of the study for the reader. Theoretical framework determines what things to measure and what statistical relationship to look 
for (Tamene 2016). A theoretical framework reflects the work the researcher engages in to use a theory in each study, whereas a conceptual framework answers the question, "Why is this research important?" and "What contributions might these findings make to what is already known?" (Varpio et al. 2019). A theory is a relationship between concepts (Ngulube 2018).

A conceptual framework is incredibly important (Crawford 2020). It is used in research work, in the absence of a grand theory (Camp 2001). Ngulube (2018) opined that the way in which data are collected and interpreted, depends on the researcher's conceptual or theoretical perspective. This implies that the research process is interlinked, with one step leading to the other. Although theoretical and conceptual frameworks are different, they heighten the quality of a research project (Adom, Hussein, and Agyem 2018). Researchers should therefore be specific on what framework is being used in a study and be explicit in explaining the framework as it relates to the research problem. The issue of using the concepts interchangeably in research should be avoided. If the work requires using aspects or some concepts from the theory, they should be applied but the researcher should mention the fact that concepts or variables from the theory were used.

Imenda (2014) opined that whole theory may serve as one's theoretical framework; a conceptual framework is normally of limited scope. There have been varying opinions of authors of what conceptual and theoretical frameworks are in research writing. Imenda (2014) remarked that there can be several researchers working on the same research problem where each one of the students investigated the problem from different theoretical or conceptual frameworks. Likewise, Kivunja (2018) looked at theoretical and conceptual frameworks from different perspectives. Although we cannot exhaust all these views, for the purpose of this study and for proper clarifications of the concepts as used in the study, theoretical framework implies when research uses the totality of a theory in a study without modifying or removing any of the concepts. Conceptual framework is when aspects or constructs from a theory are used in a research study.

More than one theory can be used in a study, as theory choice is determined by the sheer amount of data (Ma and Norwich 2007). Most authors refer to the practice of adopting more than one theory in a study as theory triangulation. Theory triangulation is the adoption of different theories to interpret data sets (Flick 2002), or using multiple perspectives to interpret a single set of data (Guion, Diehl, and McDonald 2011). In some studies, authors use more than one theory in a study, but it is used either as theoretical or as conceptual. Most times they refer to it as a theoretical framework, as opposed to triangulation which can enrich research, as it offers a variety of data sets to explain differing aspects of a phenomenon of interest (Noble and Heale 2019).

The significance of theory in research is seen by the fact that, in some studies, theories are borrowed from other disciplines in the absence of a home-based theory to explain the research variables. Authors such as Hall (2003), Kenworthy and Verbeke (2015), Oswick, Fleming and Hanlon (2011), and Ukwoma and Ngulube (2021a) have 
highlighted the essence of theory borrowing in research. Theory borrowing is common practice in all disciplines. It is a necessity because of the interdisciplinary nature of Library and Information Science (LIS) research, which cannot rely solely on homebased theories (Ukwoma and Ngulube 2021a). ODL is multidisciplinary and researchers borrow theories from other disciplines to explain their research variables when there is a need to do that. Since many disciplines tend to move towards interdisciplinary research, theory borrowing becomes a necessity. Ocholla and Le Roux (2011), when referring to the LIS discipline, highlighted that borrowing theory from another discipline does not make the LIS discipline a lesser science, likewise other disciplines. The focus of researchers in theory use should therefore be on the proper use of the theory and clear distinction of the perspectives used in each study. This will contribute significantly to the growth of research in ODL literature, hence the need for this study to highlight the way in which ODL researchers present theoretical and conceptual frameworks in their research studies.

\section{Methodology}

Using a quantitative content analysis, the researchers selected a total of 336 articles that used theory in five core ODL journals for the population of the study. The five ODL journals studied were adapted from the studies by Çakıroğlu et al. (2019), and Ukwoma and Ngulube (2021b) as core ODL journals that focus on open and distance education, and they comprise recent studies. The journals were: The American Journal of Distance Education (AJDE), Distance Education (DE), The European Journal of Open, Distance and E-Learning (EURODL), Open Learning: The Journal of Open, Distance and ELearning (OL), and The International Review of Research in Open and Distributed Learning (IRRODL). The study covered a period of nine years (2009-2018) which is long enough to know the changing pattern in scholarly communication. This period may be less in some studies, as Pendlebury (2010) highlighted that Thomson Reuters recommends at least five years of determining the publication and citation patterns.

The articles were downloaded from the websites of these journals. The articles were arranged year by year, before extracting the required information such as the theory used, the extent of theory use (either the full theory or aspect/concepts of the theory), those that used more than one theory, and those where the terms theoretical and conceptual frameworks were properly used. To ascertain these elements, the researchers read through the works to identify the concepts borrowed from the theory, where and in which way they were applied. Where the author used all the concepts from the theory, this helped the researchers to ascertain that it is a theoretical and not a conceptual framework. But when few constructs were used, the researchers grouped it as conceptual framework, and included other elements if they were clearly stated in the work as theoretical or conceptual frameworks. The extraction of these research elements was done manually and lasted for three months, from March to May 2021. The extracted data were exported to Microsoft Excel (version 10) for analysis. 
To explain some of the terms used in coding the data: Cited means the authors referred to the theory in their work without applying it in any aspect of the theory in the work. Described means that the theories were mentioned and properly explained by the researchers in the context of the study. Applied means that the researcher explained the theory and applied it in formulating the research questions or hypothesis, the design of the study, and the data collection and analysis. A theory being used in full means that the researchers used the whole components of the theory as it was propounded. Using aspects of the theory implies that the researcher adopted some concepts or constructs relevant to the study and applied them in the work. In some studies, the researchers came up with a research model using the concepts borrowed from the theory.

Based on the definition of the coding terms, the two authors coded the data separately, using five articles each, to ensure reliability of the results. After their independent coding, it was discovered that there was no disparity in their results. The remaining articles were coded following the stated guide.

\section{Results}

Table 1 shows that theories were used in the articles published in the five core ODL journals, although the number of theories used differ among these journals. Out of the 336 articles that were studied, 28.3 per cent is from $D E, 28.1$ per cent is from IRRODL, 21 per cent is from EURODL, 20.8 per cent is from $A J D E$, and 9 per cent is from $O L$.

Table 1: The extent of theory use and number of theories used in each article

\begin{tabular}{|l|l|l|l|}
\hline Journal & $\begin{array}{l}\text { Articles that } \\
\text { used theory }\end{array}$ & $\begin{array}{l}\text { Articles that } \\
\text { used one theory }\end{array}$ & $\begin{array}{l}\text { Articles that used more } \\
\text { than one theory }\end{array}$ \\
\hline$I R R O D L$ & $190(28.1 \%)$ & $160(84.2 \%)$ & $30(15.8 \%)$ \\
\hline$D E$ & $58(28.3 \%)$ & $55(94.8 \%)$ & $3(5.2 \%)$ \\
\hline$A J D E$ & $36(20.8 \%)$ & $34(94.4 \%)$ & $2(5.6 \%)$ \\
\hline$E U R O D L$ & $36(21.0 \%)$ & $35(97.2 \%)$ & $1(2.8 \%)$ \\
\hline$O L$ & $16(9 \%)$ & $15(93.8 \%)$ & $1(6.2 \%)$ \\
\hline Total & $\mathbf{3 3 6}$ & $\mathbf{2 9 9}$ & $\mathbf{3 7}$ \\
\hline
\end{tabular}

\section{To what Extent do ODL Researchers Use more than one Theory in one Study?}

ODL journals used theory, although the extent of use varies. Among the ODL journals, it shows that out of the 190 articles that used theory, in IRRODL, 84.2 per cent used one theory whereas 15.8 per cent used more than one theory. In $D E, 94.8$ per cent used one theory whereas 5.2 per cent used more than one theory. In AJDE, 94.4 per cent used one theory whereas 5.6 per cent used more than one theory. This shows that the use of one theory in a study is more prevalent among ODL journals. 
To what Extent do ODL Researchers Mention Theories and never Show the Utility of the Theory to the Study?

The use of theory in articles published in ODL journals, as presented in Table 2, shows that out of the 336 articles that were studied, 24 articles cited the theory without applying it in the research process. In some articles, the researchers referred to the theory in the literature review or introduction but in the work, there was no description regarding what the theory is and in which way it was used. In 31 articles, the theories were described by providing a full explanation of the theories and their constructs, and reference to studies that used the theory were made. In 281 articles, the theory was applied, which means that the theories were explained, reference made to studies where the theory had been used and the constructs were used to formulate either the research questions or the hypothesis, the way in which they were used in data collection and, in some cases, the author developed a research model based on the constructs borrowed from the theory. The breakdown as theory is used in each journal is provided in Table 2 .

Table 2: Level of theory use

\begin{tabular}{|l|l|l|l|l|l|}
\hline Journal & $\begin{array}{l}\text { Articles } \\
\text { that used } \\
\text { full theory }\end{array}$ & $\begin{array}{l}\text { Articles that } \\
\text { used concepts } \\
\text { from the theory }\end{array}$ & Cited & Described & Applied \\
\hline$I R R O D L$ & 148 & 42 & 15 & 20 & 155 \\
\hline$D E$ & 41 & 17 & 4 & 5 & 49 \\
\hline$A J D E$ & 31 & 5 & - & 1 & 35 \\
\hline$E U R O D L$ & 25 & 11 & 3 & 3 & 30 \\
\hline$O L$ & 13 & 3 & 2 & 2 & 12 \\
\hline Total & $\mathbf{2 5 8}$ & $\mathbf{7 8}$ & $\mathbf{2 4}$ & $\mathbf{3 1}$ & $\mathbf{2 8 1}$ \\
\hline
\end{tabular}

\section{How Many ODL Researchers Use Aspects of the Theory and still Call it a Theoretical Framework?}

Table 3 shows that a total of 78 articles used constructs from the theory without adopting the whole theory. Out of the 78 articles, 17 articles clearly stated that the constructs from the theory were used as a conceptual framework, while in 60 articles, it was stated that they were used as theoretical framework from the subheading, but reading through the work, one discovers that they used few constructs from the theory that relates to the study. 
Table 3: Articles that used concepts from theory and refer to them as theoretical framework

\begin{tabular}{|l|l|l|l|l|}
\hline Journal & $\begin{array}{l}\text { Used concepts } \\
\text { from the } \\
\text { theory }\end{array}$ & $\begin{array}{l}\text { Used } \\
\text { concepts } \\
\text { from theory } \\
\text { as } \\
\text { conceptual } \\
\text { framework/ } \\
\text { model }\end{array}$ & Triangulation & $\begin{array}{l}\text { Used } \\
\text { concepts } \\
\text { from } \\
\text { theory as } \\
\text { theoretical } \\
\text { framework }\end{array}$ \\
\hline$I R R O D L$ & 42 & 10 & 1 & 31 \\
\hline$D E$ & 17 & 5 & - & 12 \\
\hline$A J D E$ & 5 & - & & 5 \\
\hline$E U R O D L$ & 11 & 1 & - & 10 \\
\hline$O L$ & 3 & 1 & - & 2 \\
\hline Total & $\mathbf{7 8}$ & $\mathbf{1 7}$ & $\mathbf{1}$ & $\mathbf{6 0}$ \\
\hline
\end{tabular}

How Many ODL Researchers Use Many Theories and still Call them a Theoretical Framework without a Focus on Theory Triangulation?

Table 4 shows that in IRRODL, out of the 30 articles that used more than one theory, 27 referred to them as a theoretical framework, whereas in 3 articles, it was triangulated. In the remaining journals, $D E, A J D E, E U R O D L$ and $O L$, they were all referred to as a theoretical framework. This implies that theory triangulation is not prevalent in ODL research among the journals studied.

Table 4: Articles that used more than one theory and refer to them as theoretical framework

\begin{tabular}{|l|l|l|l|l|}
\hline Journal & $\begin{array}{l}\text { Articles that } \\
\text { used more } \\
\text { than one } \\
\text { theory }\end{array}$ & Theoretical & Conceptual & Triangulation \\
\hline$I R R O D L$ & 30 & 27 & - & 3 \\
\hline$D E$ & 3 & 3 & - & - \\
\hline$A J D E$ & 2 & 2 & - & - \\
\hline$E U R O D L$ & 1 & 1 & - & - \\
\hline$O L$ & 1 & 1 & - & - \\
\hline Total & 37 & 34 & - & 3 \\
\hline
\end{tabular}




\section{To what Extent do ODL Researchers Borrow Theories from Other Disciplines?}

Table 5 shows the disciplines ODL researchers borrow theories from, which are mostly education, sociology, psychology and information systems. This is also the situation in the individual journals. Although ODL cuts across many disciplines, it is mostly classified under education, therefore the major disciplines where theories are borrowed from include sociology, psychology and information systems.

Table 5: Disciplines ODL researchers borrow theories from

\begin{tabular}{|c|c|c|c|c|c|c|}
\hline $\begin{array}{l}\text { Journal } \\
\text { Discipline }\end{array}$ & IRRODL & $\overline{D E}$ & $A J D E$ & EURODL & $O L$ & Total \\
\hline Anthropology & $10(4.4 \%)$ & $2(3.0 \%)$ & 3(6.9\%) & $2(5.4 \%)$ & - & 17 \\
\hline Communication & $4(1.7 \%)$ & $2(3.0 \%)$ & $1(2.3 \%)$ & - & - & 7 \\
\hline $\begin{array}{l}\text { Computer } \\
\text { Science }\end{array}$ & $2(0.8 \%)$ & - & - & - & - & 2 \\
\hline Economics & $2(0.8 \%)$ & $1(1.5 \%)$ & - & - & - & 3 \\
\hline Education & $47(21.0 \%)$ & $15(23.0 \%)$ & $20(46.5 \%)$ & $11(29.7 \%)$ & $4(23.5 \%)$ & 97 \\
\hline $\begin{array}{l}\text { Health } \\
\text { Communication }\end{array}$ & $1(0.4 \%)$ & - & - & - & - & 1 \\
\hline $\begin{array}{l}\text { Information } \\
\text { Systems }\end{array}$ & $37(16.5 \%)$ & 2(3.0\%) & 3(6.9\%) & - & $2(11.7 \%)$ & 44 \\
\hline $\begin{array}{l}\text { Knowledge } \\
\text { Management }\end{array}$ & $1(0.4 \%)$ & - & $1(2.3 \%)$ & - & - & 2 \\
\hline Management & - & $1(1.5 \%)$ & - & - & - & 1 \\
\hline Marketing & - & $1(1.5 \%)$ & - & - & - & 1 \\
\hline Mathematics & $4(1.7 \%)$ & - & - & - & - & 4 \\
\hline Medicine & - & $1(1.5 \%)$ & - & - & - & 1 \\
\hline Music & - & - & - & $1(2.7 \%)$ & - & 1 \\
\hline Political science & $2(0.8 \%)$ & $2(3.0 \%)$ & - & - & - & 4 \\
\hline Psychology & $44(19.7 \%)$ & $12(18.4 \%)$ & $9(20.9 \%)$ & $13(35.1 \%)$ & $9(52.9 \%)$ & 87 \\
\hline Science & $7(3.1 \%)$ & - & - & $3(8.1 \%)$ & - & 10 \\
\hline Sociology & $51(22.8 \%)$ & $26(40 \%)$ & $4(9.3 \%)$ & $6(16.2 \%)$ & $2(11.7 \%)$ & 89 \\
\hline $\begin{array}{l}\text { Strategic } \\
\text { Management }\end{array}$ & $1(0.4 \%)$ & - & - & - & - & 1 \\
\hline Theatre Art & $1(0.4 \%)$ & - & - & - & - & 1 \\
\hline Tourism & $1(0.4 \%)$ & - & - & - & - & 1 \\
\hline
\end{tabular}

\section{Discussion}

ODL researchers use theory in their research and this could be seen from the results on theory use in ODL journals. Although the use of theory varies among these ODL journals, 299 articles used one theory, with 37 using more than one theory in a study. This could be based on the subject area of the article, although some authors fail to make proper use of the theory in their research. Adom, Hussein and Agyem (2018) stated that 
many researchers apply the two concepts incorrectly in their research work. Misconception and misuse of theory has been seen in many studies, and ODL researchers are no exception as it was also discovered that researchers mentioned theories without utilising them in their research work. A total of 24 authors just cited the theory, whereas in a total of 31 articles, the theories were described with full explanations and references were made to previous studies where they were used. However, in 281 articles, the theories were properly applied in forming the research questions, hypothesis, research design, data collection and analysis. This shows that many ODL researchers do not fall prey to the misconception in theory use, they still differentiate between theoretical and conceptual frameworks.

In using these theories, most researchers used all the constructs in the theory as could be seen from the findings, while 78 adapted only a few constructs based on the research problems. However, the researchers, when using these constructs, failed to clearly state if they were used as conceptual framework. Some misconceptions were identified in using the constructs from the theory; 60 articles that used constructs from theory still referred to them as theoretical framework. Only 17 articles clarified their use of the constructs as a conceptual framework and not a theoretical framework. Conceptual framework is incredibly important (Crawford 2020) - it is used in research work, in the absence of a grand theory (Camp 2001). The relevance of conceptual and theoretical frameworks is summarised in the statement by Ngulube (2018), that the way in which data are collected and interpreted depends on the researcher's conceptual or theoretical perspective. Therefore, ODL researchers should be guided in the research to ensure they make proper use of the two concepts and clearly state when each one is used, to avoid misconception. The use of theory triangulation is not prevalent in ODL research, which shows that the researchers need to focus more on theory triangulation in their research.

Considering the benefits of theory in a study, authors such as Hall (2003), Kenworthy and Verbeke (2015), Oswick, Fleming and Hanlon (2011), and Ukwoma and Ngulube (2021a) highlighted the essence of theory borrowing in research. Borrowing theories from other disciplines is applicable to all disciplines, especially with the interdisciplinary nature of many studies. ODL researchers borrowed theories across many disciplines, not only education. The heavy reliance on subject areas such as sociology, psychology and information systems could be attributed to the subject areas and the reliance on technology in the teaching and learning in ODL. ODL is facilitated by using technology, and therefore ascertaining the users' perceptions and attitude regarding students when using these technologies is important for effective teaching and learning.

\section{Conclusion}

The use of theory in research is essential as it helps in the production of transformative knowledge (Ngulube 2020). ODL researchers use theory in their research study; the use of one theory in a study is more prevalent in ODL research articles studied. Although 
in some articles there were misconceptions about what the researchers referred to as theoretical framework, that emphasis should be laid on the distinction between theoretical and conceptual framework to minimise this misconception. The multidisciplinary nature of ODL research encouraged borrowing theory from other disciplines. ODL centres on the use of technology to enhance teaching and learning, as a result, ODL researchers tend to explore various ways of using these technologies to connect the user with the learning environment, hence the reliance on theories from information systems, psychology and sociology. Theory triangulation has not made significant inroads into ODL research, as it was discovered from the study. The researchers are therefore of the view that ODL research should focus more on theory triangulation. Theory triangulation can enrich research as it offers a variety of data sets to explain different aspects of a phenomenon of interest (Noble and Heale 2019).

\section{References}

Adom, D., E. K. Hussein, and J. A. Agyem. 2018. "Theoretical and Conceptual Framework: Mandatory Ingredients of a Quality Research.” International Journal of Scientific Research 7 (1): 436-41.

Çakıroğlu, Ü., M. Kokoç, S. Gökoğlu, M. Öztürk, and F. Erdoğdu. 2019. “An Analysis of the Journey of Open and Distance Education: Major Concepts and Cutoff Points in Research Trends." International Review of Research in Open and Distributed Learning 20 (1): 1-20. https://doi.org/10.19173/irrodl.v20i1.3743.

Camp, W. G. 2001. "Formulating and Evaluating Theoretical Frameworks for Career and Technical Education." Career and Technical Education Research 26 (1): 4-25. https://doi.org/10.5328/JVER26.1.4.

Crawford, L. M. 2020. Conceptual and Theoretical Frameworks in Research. Thousand Oaks: Sage.

Flick, U. 2002. An Introduction to Qualitative Research. 2nd ed. Thousand Oaks: Sage.

Guion, L. A., D. C. Diehl, and D. McDonald. 2011. "Triangulation: Establishing the Validity of Qualitative Studies.” IFAS Extension 8. https://doi.org/10.32473/edis-fy394-2011.

Hall, H. 2003. "Borrowed Theory Applying Exchange Theories in Information Science Research." Library and Information Science Research 25: 287-306. https://doi.org/10.1016/S0740-8188(03)00031-8.

Imenda, S. 2014. "Is there a Conceptual Difference between Theoretical and Conceptual Frameworks?" Journal of Social Sciences 38 (2): 185-195. https://doi.org/10.1080/09718923.2014.11893249. 
Kenworthy, T. P., and A. Verbeke. 2015. "The Future of Strategic Management Research: Assessing the Quality of Theory Borrowing.” European Management Journal 33 (3): 179190. https://doi.org/10.1016/j.emj.2015.03.007.

Kitchel, T., and A. L. Ball. 2014. "Quantitative Theoretical and Conceptual Framework Use in Agricultural Education Research.” Journal of Agricultural Education 55 (1): 186-199. https://doi.org/10.5032/jae.2014.01186186.

Kivunja, C. 2018. "Distinguishing between Theory, Theoretical Framework, and Conceptual Framework: A Systematic Review of Lessons from the Field." International Journal of Higher Education 7 (6): 44-53. https://doi.org/10.5430/ijhe.v7n6p44.

Ma, A., and B. Norwich. 2007. "Triangulation and Theoretical Understanding.” International Journal of Social Research Methodology 10 (3): 211-26. https://doi.org/10.1080/1364557070154187.

Ngulube, P. 2018. "Overcoming the Difficulties associated with Using Conceptual and Theoretical Frameworks in Heritage Studies." In Handbook of Research on Heritage Management and Preservation, edited by P. Ngulube, 1-23. Hershey: IGI Global. https://doi.org/10.4018/978-1-5225-3137-1.ch001.

Ngulube, P. 2020. "Theory and Theorising in Information Science Scholarship.” In Handbook of Research on Connecting Research Methods for Information Science Research, edited by P. Ngulube, 8-39. Hershey: IGI Global. https://doi.org/10.4018/978-1-7998-1471-9.ch002.

Noble, H., and R. Heale. 2019. "Triangulation in Research, with Examples." Evidenced-Based Nursing 22 (3): 67-68. https://doi.org/10.1136/ebnurs-2019-103145.

Ocholla, D. N., and J. le Roux. 2011. "Conceptions and Misconceptions of Theoretical Frameworks in Library and Information Science Research: A Case Study of Selected Theses and Dissertations from Eastern and Southern African Universities." Mousaion 29 (2): 61-74.

Oswick, C., P. Fleming, and G. Hanlon. 2011. "From Borrowing to Blending." Academy of Management Review 36 (2): 318-37. https://doi.org/10.5465/AMR.2011.59330932.

Pendlebury, D. A. 2010. White Paper: Using Bibliometrics in Evaluating Research. Philadelphia: Thomson Reuters.

Tamene, E. H. 2016. “Theorizing Conceptual Framework.” Asian Journal of Educational Research 4 (2): 50-56.

Ukwoma, S. C., and P. Ngulube. 2021a. "To Borrow or not to Borrow is the Question? Theory Borrowing in Library Information Science Postgraduate Research in Nigeria and South Africa." International Information and Library Review 53 (1): 48-62. https://doi.org/10.1080/10572317.2020.1790261. 
Ukwoma, S. C., and P. Ngulube. 2021b. "Trends and Patterns of Theory Use in Open and Distance Education Research Journals 2009-2018." Open Learning: The Journal of Open, Distance and e-Learning. https://doi.org/10.1080/02680513.2021.1911793.

Varpio, L., E. Paradis, S. Uijtdehaage, and M. Young. 2019. "The Distinctions between Theory, Theoretical Framework, and Conceptual Framework." Academic Medicine: Journal of the Association of American Medical Colleges 95 (7): 989-94. https://doi.org/10.1097/ACM.0000000000003075. 